\title{
Hepatic Leukostasis and Hypoxic Stress in Adhesion Molecule-deficient Mice After Gut Ischemia/Reperfusion
}

\author{
Yoshinori Horie, ${ }^{\star}$ Robert Wolf, ${ }^{\ddagger}$ Donald C. Anderson, ${ }^{\S}$ and D. Neil Granger ${ }^{\star}$ \\ $*$ Department of Physiology and ${ }^{\ddagger}$ Department of Medicine, Louisiana State University Medical Center, Shreveport, Louisiana 71130 ; \\ and ${ }^{\S}$ Discovery Research, Pharmacia-UpJohn Laboratories, Kalamazoo, Michigan 49001
}

\begin{abstract}
The concept that leukocyte-endothelial cell adhesion (LECA) is a major determinant of the tissue injury elicited by ischemia/reperfusion ( $I / R)$ is largely based on studies employing adhesion molecule-specific monoclonal antibodies. The objective of this study was to assess the contribution of LECA to I/R injury using mutant mice (all on a C57Bl background) that are deficient in either intracellular adhesion molecule-1, P-selectin, or CD11/CD18. The accumulation of fluorescently labeled leukocytes and the number of nonperfused sinusoids in livers of control and adhesion molecule-deficient mice were monitored by intravital microscopy for $1 \mathrm{~h}$ after release of the occluded (for $15 \mathrm{~min}$ ) superior mesenteric artery. Autofluorescence of pyridine nucleotide (NADH) was measured as an indicator of mitochondrial $\mathrm{O}_{2}$ consumption and redox status. The number of stationary leukocytes in the liver after gut $I / R$ was significantly elevated compared with baseline values in C57Bl (control) mice. Autofluorescence of NADH was also significantly increased (indicating hypoxia) after $I / R$ in these mice, especially in the pericentral region. Intercellular adhesion molecule-1-, CD11/CD18-, and P-selectin-deficient mice all exhibited a blunted leukosequestration response to $\mathbf{I} / \mathbf{R}$ and smaller increments in nonperfused sinusoids, relative to C57Bl mice. All adhesion molecule-deficient mice also exhibited an attenuated increment in NADH autofluorescence in the pericentral region, relative to control mice. These results from adhesion molecule-deficient mice provide additional support for the view that LECA is an important determinant of the liver dysfunction induced by gut I/R. (J. Clin. Invest. 1997. 99:781-788.) Key words: leukocyte adhesion $-\mathrm{P}$-selectin $\bullet$ intercellular adhesion molecule-1 • tissue hypoxia $\bullet$ hepatocellular injury
\end{abstract}

\section{Introduction}

Reperfusion of ischemic tissues results in an acute inflammatory response that is characterized by an increased fluid filtration and steric hindrance (plugging) of circulating blood cells

Address correspondence to D. Neil Granger, Department of Physiology, LSU Medical Center, 1501 Kings Highway, Shreveport, LA 71130-3932. Phone: 318-675-6011; FAX: 318-675-6005; E-mail: dgrang@ lsumc.edu

Received for publication 18 September 1996 and accepted in revised form 2 December 1996.

J. Clin. Invest.

(C) The American Society for Clinical Investigation, Inc.

0021-9738/97/02/0781/08 \$2.00

Volume 99, Number 4, February 1997, 781-788 in capillaries, with a concomitant recruitment of adherent and emigrating leukocytes and increased albumin extravasation in downstream postcapillary venules (1-7). The results of numerous studies suggest that there is a cause-effect relationship between the accumulation of inflammatory cells and the microvascular (and parenchymal cell) dysfunction that are elicited by ischemia/reperfusion (I/R). ${ }^{1}$ Indeed, several strategies have been employed to assess the contribution of adherent leukocytes to the tissue injury associated with I/R. These include protocols employing: $(a)$ filters that entrap and consequently remove circulating leukocytes (4), (b) agents that inhibit the production (e.g., vinblastine) of circulating leukocytes (8), (c) antibodies that form immune complexes with and subsequently eliminate circulating leukocytes $(5,9)$, or $(d)$ monoclonal antibodies that immunoneutralize adhesion molecules expressed on activated leukocytes or endothelial cells (6-7, 10). The effectiveness of adhesion molecule-specific mAbs in attenuating I/R-induced tissue injury has lead to the widely held view that leukocyte-endothelial cell adhesion is a ratelimiting step in the pathogenesis of this reperfusion injury.

We have recently employed adhesion molecule-specific mAbs to address the contribution of leukocyte-endothelial cell adhesion and the specific role of different endothelial cell and leukocyte adhesion molecules to the hepatocellular dysfunction associated with gut I/R (11). Our findings indicate that either rendering rats neutropenic with anti-neutrophil serum or administration of mAbs directed against either CD11/ CD18 or intercellular adhesion molecule-1 (ICAM-1) results in a blunted accumulation of leukocytes and a reduction in the hypoxic stress that occurs in proximity to nonperfused sinusoids after gut I/R. While adhesion molecule-specific mAbs have proven to be powerful tools for addressing the role of leukocytes in different models of inflammation, there are some uncertainties and potential limitations of this experimental approach that detracts from the $\mathrm{mAbs}^{1}$ usefulness as blocking reagents in vivo. For example, it has been recently proposed that antibodies to ICAM-1 trigger a response in endothelial cells that might confer protection against $\mathrm{I} / \mathrm{R}$ injury via a mechanism that is unrelated to the blocking function of the antibody (12).

Mice that are genetically and functionally deficient in leukocyte or endothelial cell adhesion molecules represent a novel alternative approach to antibody experiments for defining the contribution of leukocytes to the pathogenesis of $\mathrm{I} / \mathrm{R}$ injury. This genetic ablation approach avoids the potential problems associated with interpretation of antibody studies and provides a unique opportunity to assess the absolute requirements for specific adhesion molecules in mounting acute

1. Abbreviations used in this paper: ALT, alanine aminotransferase; $\mathrm{I} / \mathrm{R}$, ischemia/reperfusion; ICAM, intercellular adhesion molecule; THV, terminal hepatic venules. 
or chronic inflammatory responses. The objective of the present study was to determine whether the livers of mice that are genetically deficient in either CD11/CD18, ICAM-1, or $\mathrm{P}$-selectin are confered protection (relative to control mice) against the deleterious effects of gut I/R. Intravital videomicroscopic techniques were employed to monitor and quantify leukostasis (adherence and plugging) in different regions (midzonal and pericentral) of the liver microcirculation, the number of nonperfused sinusoids, and NADH autofluorescence (an index of tissue hypoxia) after gut I/R.

\section{Methods}

Animals. All mice (8-12 wk old) used in this study were of a C57Bl background. Wild-type (control) mice were obtained from Harlan Sprague Dawley, Inc. (Indianapolis, IN), while the ICAM-1-deficient (13), CD11/CD18-deficient (14), and P-selectin knock-out (15) mice were obtained from Pharmacia-UpJohn Laboratories. The mutants were all developed in the 129 mouse strain and the number of back crosses to C57Bl ranged between 8 (P-selectin) and 10 (CD18 and ICAM-1) generations. All of the mice were obtained at 4 wk of age and maintained on standard mouse chow until $18 \mathrm{~h}$ before the experiment.

Surgical procedure. After administration of atropine sulfate (0.04 $\mathrm{mg} / \mathrm{kg}$ body wt i.p.), the mice were anesthetized with ketamine hydrochloride $(150 \mathrm{mg} / \mathrm{kg}$ body wt i.m.) and xylazine $(7.5 \mathrm{mg} / \mathrm{kg}$ body wt i.m.). The right carotid artery was cannulated and systemic arterial pressure was measured with a pressure transducer (Statham P23A; Gould Inc., Oxnard, CA) connected to the carotid artery cannula. Systemic blood pressure and heart rate were continuously recorded with a physiological recorder (Grass Instruments Co., Quincy, MA). The left jugular vein was also cannulated for drug administration. After laparotomy, the superior mesenteric artery (SMA) was occluded with a microvascular clip for 0 (sham) or $15 \mathrm{~min}$. After the ischemic period, the clip was gently removed. Estimates of blood flow using laser Doppler flowmetry indicates that ligation of the SMA results in an $\sim 70 \%$ reduction in blood flow in mouse liver.

Intravital microscopy. Immediately after removing the clip, the mouse was placed on a microscope stage. A lobe of liver was observed with an inverted intravital microscope (TMD-2S, Diaphot; Nikon Inc., Tokyo, Japan) assisted by a silicon-intensified target camera (C-2400-08; Hamamatsu photonics, Shizuoka, Japan). The liver was placed on an adjustable plexiglas microscope stage with a nonfluorescent coverslip that allowed for observation of a 2- $\mathrm{cm}^{2}$ segment of tissue. The liver was carefully placed to minimize the influence of respiratory movements. The liver surface was moistened and covered with cotton gauze soaked with saline. Images of the microcirculation near the surface of the liver was observed through a $40 \times$ fluorescent objective lens (Fluor 40/0.85; Nikon Inc.). The microfluorographs were recorded on videotape using a videocassette recorder (NV8950; Panasonic, Tokyo, Japan). A video time-date generator (WJ810; Panasonic) projected the stopwatch function onto the monitor.

Analysis of leukocyte accumulation and perfusion in liver microcirculation. Leukocytes were labeled in vivo with rhodamine-6G (2 $\mathrm{mg}$ was dissolved in $5 \mathrm{ml}$ of $0.9 \%$ saline) using a modification of a previously described method employed in rat studies $(16,17)$. It has recently been shown that rhodamine-6G selectively stains white blood cells and platelets, but not endothelial cells (16). Thus, the fluorochrome allows for differentiation between adherent leukocytes and endothelial cells. Rhodamine-6G (0.4 ml/100 g body wt) was injected before gut reperfusion, with subsequent injections every $30 \mathrm{~min}$. Rhodamine-6G-associated fluorescence was visualized by epi-illumination at $510-560 \mathrm{~nm}$, using a $590-\mathrm{nm}$ emission filter. The number of stationary leukocytes was determined off-line during playback of videotape images. A leukocyte was considered stationary within the microcirculation (sinusoids) if it remained stationary for more than $10 \mathrm{~s}$.
And the sinusoid was considered perfused if the labeled white blood cells or platelets were observed moving through it. The percentage of nonperfused sinusoids was calculated as the ratio of the number of nonperfused sinusoids to the total number of sinusoids per viewing field. Stationary leukocytes were quantified in both the midzonal and pericentral regions of the liver lobule and expressed as the number per field of view $\left(8.3 \times 10^{4} \mu \mathrm{m}^{2}\right)$.

Analysis of autofluorescence of pyridine nucleotide. Autofluorescence of pyridine nucleotide (NADH) was measured as an indicator of mitochondrial $\mathrm{O}_{2}$ consumption using the same intravital microscopy system. Autofluorescence of NADH has been used as a measure of the redox state in various tissues (18-22). However, the results of a recent report (22) suggests that ultraviolet-elicited intrahepatic autofluorescence also reflects vitamin A. Thus, to eliminate intrinsic vitamin A autofluorescence, which is mainly found in fat droplets of Ito cells, we exposed the liver surface to ultraviolet epi-illumination for $20 \mathrm{~s}$; this period was enough to abolish vitamin A autofluorescence because of its rapid photobleaching properties. Autofluorescence of NADH was visualized with a silicon-intensified target camera by epiillumination at $300-360 \mathrm{~nm}$, using a $450-\mathrm{nm}$ emission filter. Autofluorescence of NADH in both pericentral and midzonal regions of the liver were recorded on videotape immediately after quantification of leukocyte accumulation and measured with a computer-assisted digital imaging processor (National Institutes of Health Image 1.35 on a Macintosh computer). The temporal changes of autofluorescence intensity of NADH $\left[\mathrm{I}_{\mathrm{NADH}}(\mathrm{x}, \mathrm{y}, \mathrm{t})\right.$, (count/pixel)] were calculated according to the following equation:

$$
\begin{array}{r}
\% \mathrm{I}_{\mathrm{NADH}}(\mathrm{x}, \mathrm{y}, \mathrm{t})=\left\{\left[\mathrm{I}_{\mathrm{NADH}}(\mathrm{x}, \mathrm{y}, \mathrm{t})-\mathrm{I}_{\mathrm{BG}}(\mathrm{x}, \mathrm{y}, \mathrm{t})\right] /\right. \\
\left.\left[\mathrm{I}_{\mathrm{NADH}}(\mathrm{X}, \mathrm{Y}, 15)-\mathrm{I}_{\mathrm{BG}}(\mathrm{X}, \mathrm{Y}, 15)\right]\right\} \times 100(\%)
\end{array}
$$

where $\mathrm{I}_{\mathrm{BG}}(\mathrm{x}, \mathrm{y}, \mathrm{t})$ is the background intensity, which was measured in the center of terminal hepatic venules (THV).

Experimental protocols. The superior mesenteric artery was occluded with a microvascular clip for 0 (sham) or $15 \mathrm{~min}$. After the ischemic period, the clip was gently removed. Leukocyte accumulation, autofluorescence of NADH, and the number of nonperfused sinusoids were measured at 15 -min intervals for a total of $60 \mathrm{~min}$ after reperfusion. This protocol was applied to wild-type (control), CD11/ CD18-deficient, ICAM-1-deficient, and P-selectin-deficient mice. In some experiments, RB40.34 (2 mg/kg), a rat IgG2 against mouse P-selectin (PharMingen, San Diego, CA) (23) was injected intravenously (immediately before occlusion of superior mesenteric artery) into mice that are genetically deficient in ICAM-1. This P-selectinspecific $\mathrm{mAb}$ has been shown to stain venular endothelium in wildtype mice, while not staining microvessels in mice deficient in the P-selectin gene (24).

Enzyme assay. Blood samples were collected from the carotid artery after obtaining the 60-min reperfusion measurements. Serum alanine aminotransferase (ALT) activity was determined from these samples using a spectrophotometric assay obtained as a commercial kit (Sigma Chemical Co., St. Louis, MO).

Statistics. The data were analyzed using standard statistical analyses; i.e., one-way ANOVA and Scheffe's (post-hoc) test. All values are reported as mean \pm SEM, with at least five mice per group. Statistical significance was set at $P<0.05$.

\section{Results}

Table I compares the differences in leukostasis, percentage of nonperfused sinusoids, NADH autofluorescence, and plasma ALT activities in wild-type mice and mice that are genetically deficient in either ICAM-1, CD11/CD18, or P-selectin at 60 min after sham operation (basal levels). There were no significant differences between the four groups for all measured variables.

Fig. 1 compares the time course of the changes in leukocyte 
Table I. Basal Levels of Stationary Leukocytes, Nonperfused Sinusoids, NADH Autofluorescence, and Plasma ALT Activities in Wild-Type and Adhesion Molecule-deficient Mice

\begin{tabular}{|c|c|c|c|c|c|c|c|}
\hline & \multicolumn{3}{|c|}{ Stationary leukocytes (per field) } & \multirow[b]{2}{*}{ NPS* $(\%)$} & \multicolumn{2}{|c|}{ NADH autofluorescence (\%) } & \multirow[b]{2}{*}{$\operatorname{ALT}(\mathrm{IU} / \mathrm{L})$} \\
\hline & Midzonal & Pericentral & THV & & Midzonal & Pericentral & \\
\hline Wild-type & $2.2 \pm 0.20$ & $0.90 \pm 0.10$ & $0.20 \pm 0.13$ & $9.9 \pm 1.5$ & $111.0 \pm 3.0$ & $127.0 \pm 6.0$ & $19.2 \pm 2.2$ \\
\hline ICAM-1 (-) & $1.8 \pm 0.58$ & $1.4 \pm 0.51$ & $0.20 \pm 0.20$ & $10.4 \pm 1.5$ & $117.3 \pm 1.9$ & $125.0 \pm 0.7$ & $23.3 \pm 3.4$ \\
\hline CD18 $(-)$ & $2.0 \pm 0.31$ & $1.2 \pm 0.37$ & $0.60 \pm 0.24$ & $10.6 \pm 1.3$ & $116.2 \pm 2.2$ & $125.9 \pm 3.5$ & $25.1 \pm 3.1$ \\
\hline P-sel (-) & $1.2 \pm 0.20$ & $1.6 \pm 0.51$ & $0.20 \pm 0.20$ & $9.4 \pm 1.1$ & $115.1 \pm 3.6$ & $122.2 \pm 3.0$ & $20.8 \pm 1.5$ \\
\hline
\end{tabular}

*NPS, nonperfused sinusoids.

accumulation in the midzonal (Fig. $1 A$ ) and pericentral (Fig. 1 $B)$ regions of the liver microcirculation, in the terminal hepatic venules (Fig. $1 C$ ) and total number of accumulated leukocytes (Fig. $1 \mathrm{D}$ ) after $15 \mathrm{~min}$ of ischemia and $60 \mathrm{~min}$ of reperfusion.
The recruitment of leukocytes in postischemic livers was compared with the leukocyte accumulation noted in control (sham ischemic) livers. In postischemic livers, leukocyte accumulation was significant $15 \mathrm{~min}$ after reperfusion in the midzonal
$\mathbf{A}$

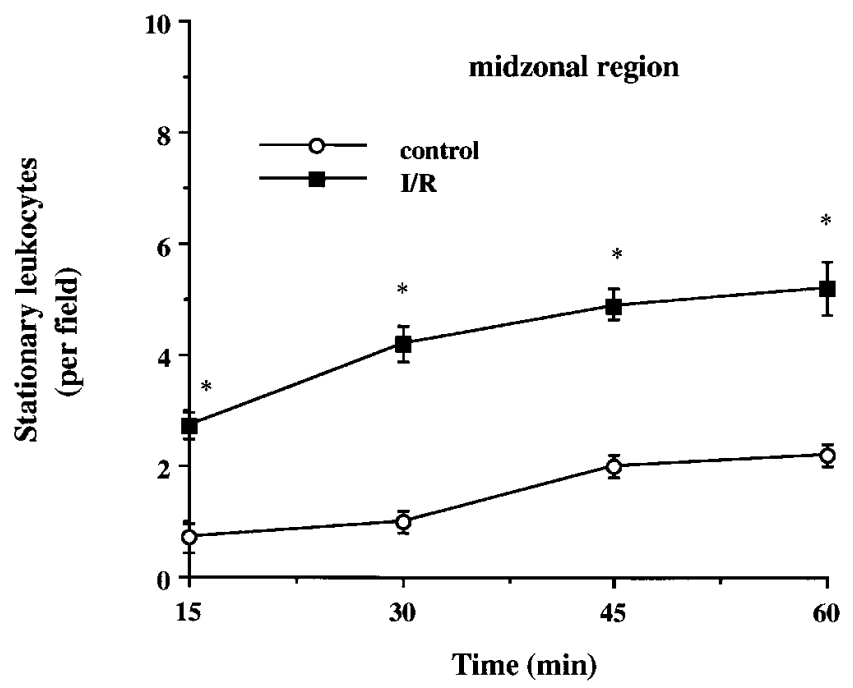

C

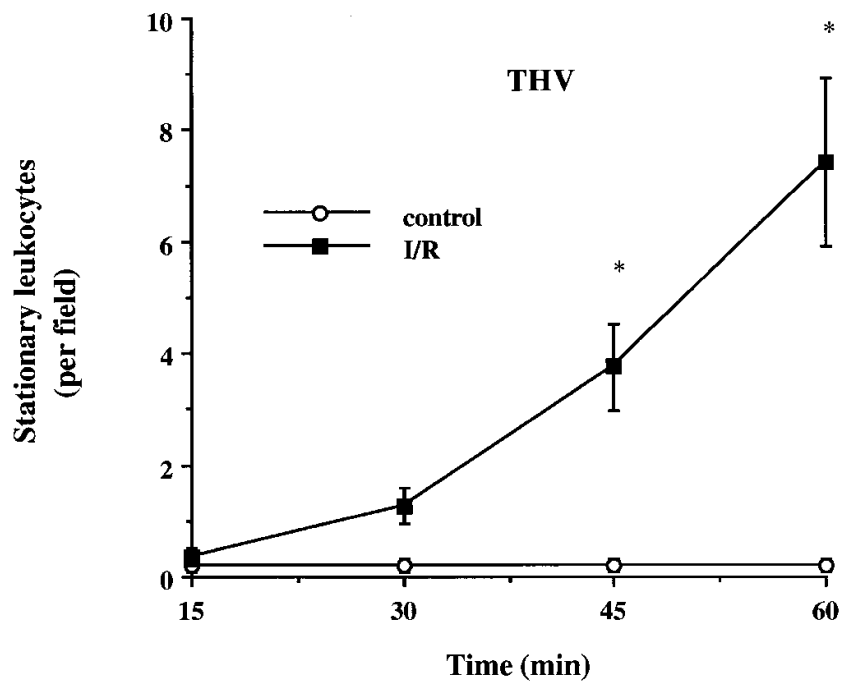

B
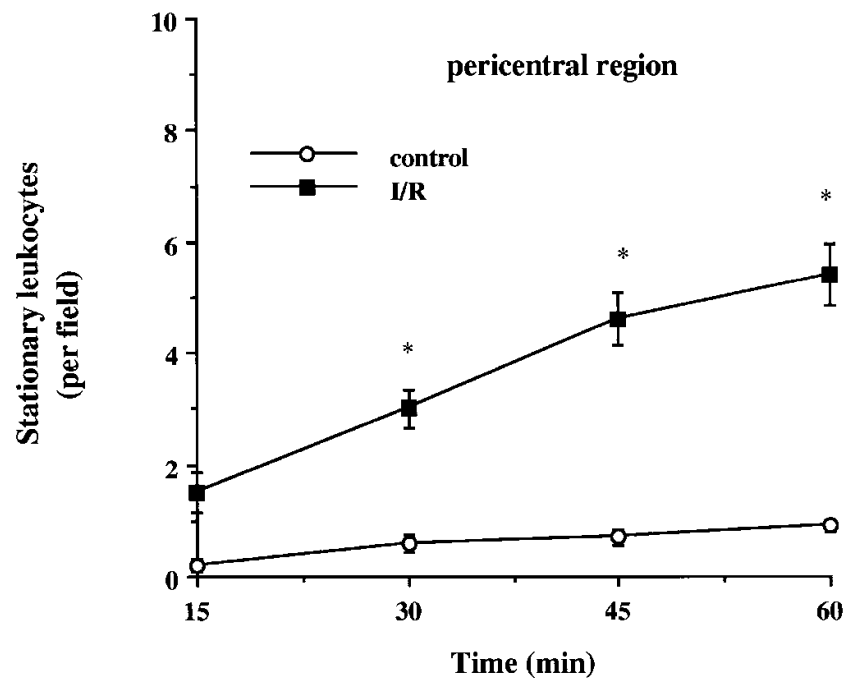

D

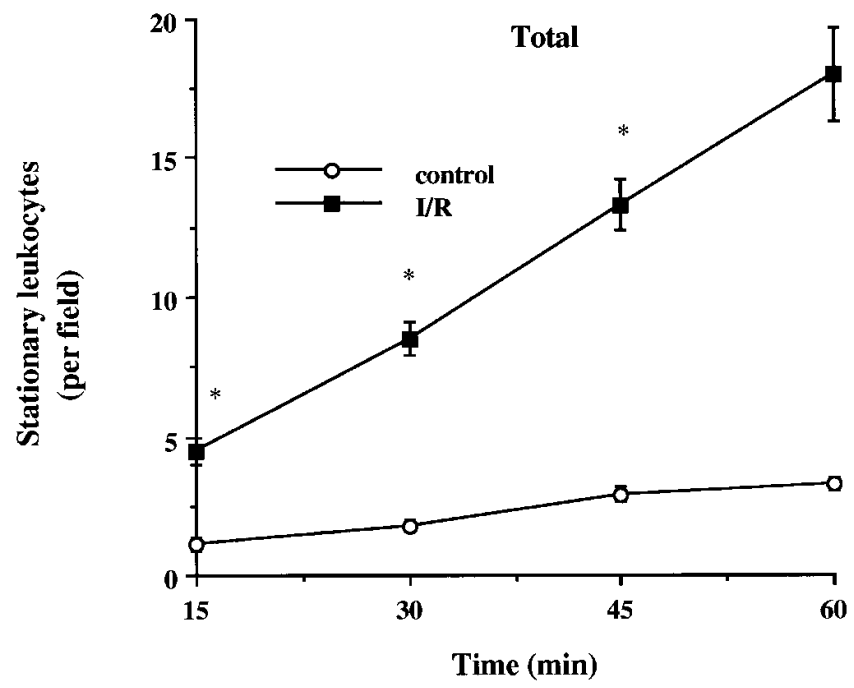

Figure 1. Time course of accumulation of stationary leukocytes in the midzonal region $(A)$, pericentral region $(B)$, and terminal hepatic venules and total (combined) liver lobule $(D)$ after exposure of the gut to ischemia and reperfusion. $n=10$ in the control group, while $n=12$ in the ischemia/reperfusion group. ${ }^{*} P<0.05$ vs. control. 


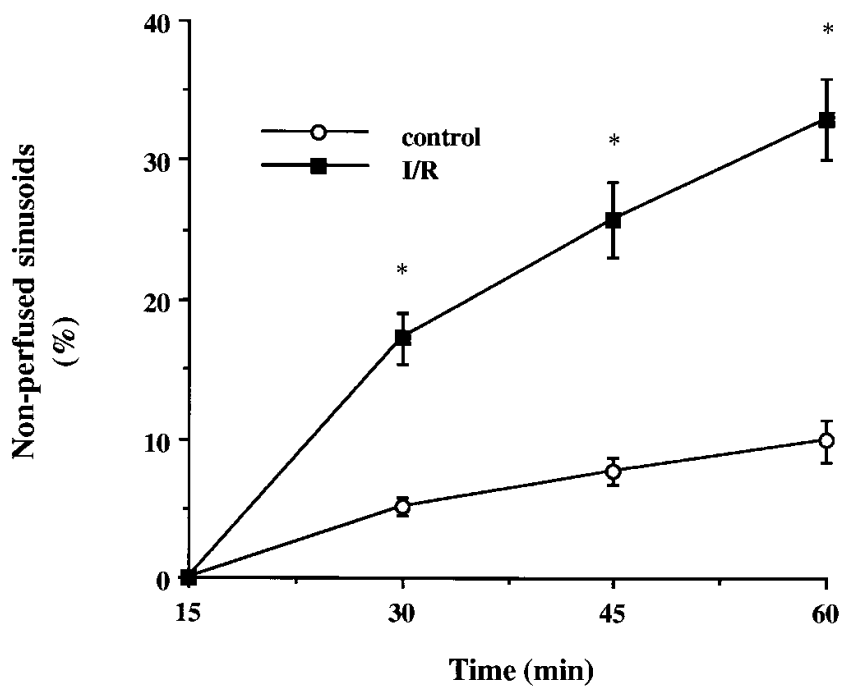

$\mathbf{A}$

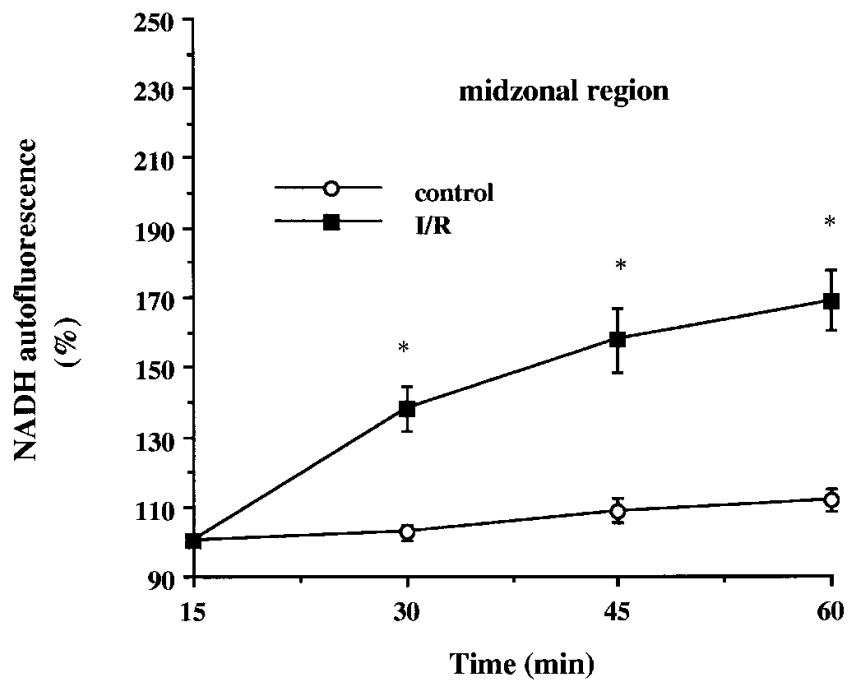

C

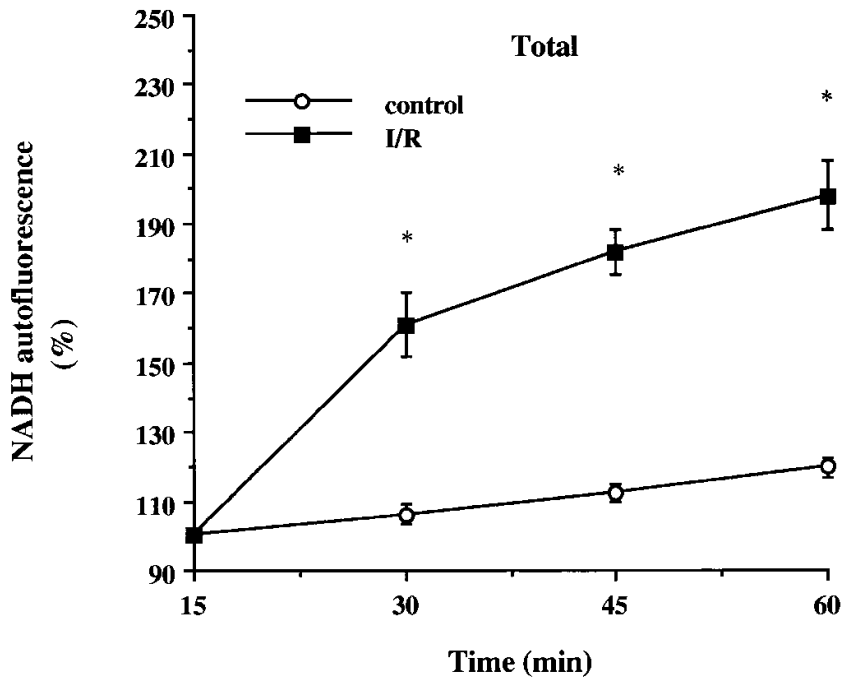

region, while 30 and 45 min were required for a significant response in the pericentral region and the THV. In the midzonal region, the number of stationary leukocytes $15 \mathrm{~min}$ after reperfusion were already elevated and increased gradually thereafter. A more impressive increase in stationary leukocytes after gut I/R was noted in the pericentral region. Similarly, leukocyte accumulation increased $>10$ times baseline values in THV within the first hour after gut I/R. Although the midzonal and pericentral sinusoidal responses to gut $I / R$ in mice were significantly blunted relative to previous observations reported for rat liver, the leukocyte adhesion responses noted in THV of mice were much greater than in rats (11).

Figure 2. The time course of changes in the percentage of nonperfused sinusoids in rat liver after gut ischemia/reperfusion. $n=10$ in the control group, while $n=12$ in the ischemia/reperfusion group. $* P<0.05$ vs. control.
B

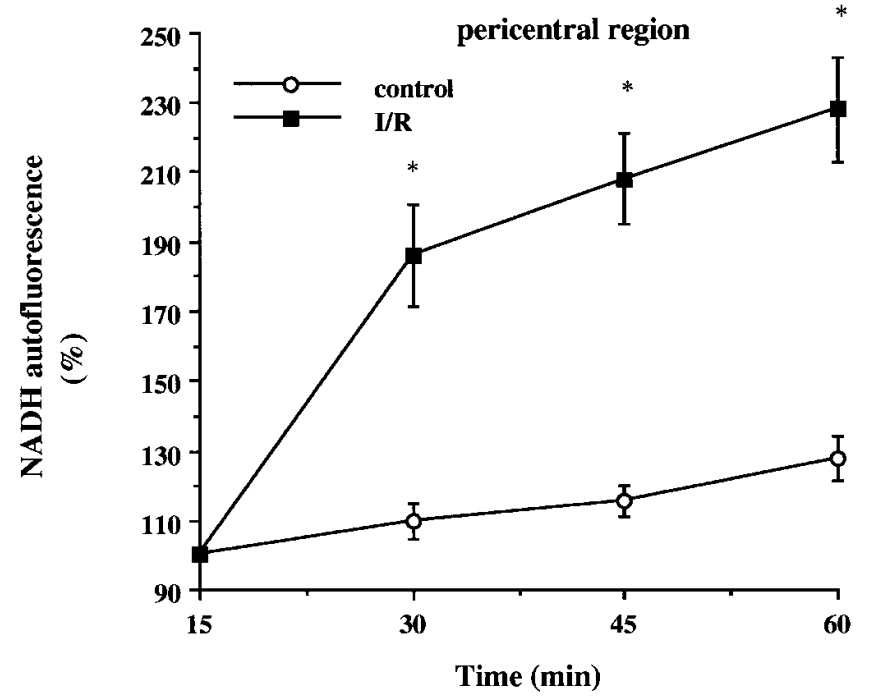

Figure 3. Time course of changes in NADH autofluorescence intensity in the midzonal region $(A)$, pericentral region $(B)$ and total (combined) liver lobule $(C)$ after exposure of the gut to ischemia and reperfusion. $n=10$ in the control group, while $n=12$ in the ischemia/reperfusion group. $* P<0.05$ vs. control. 


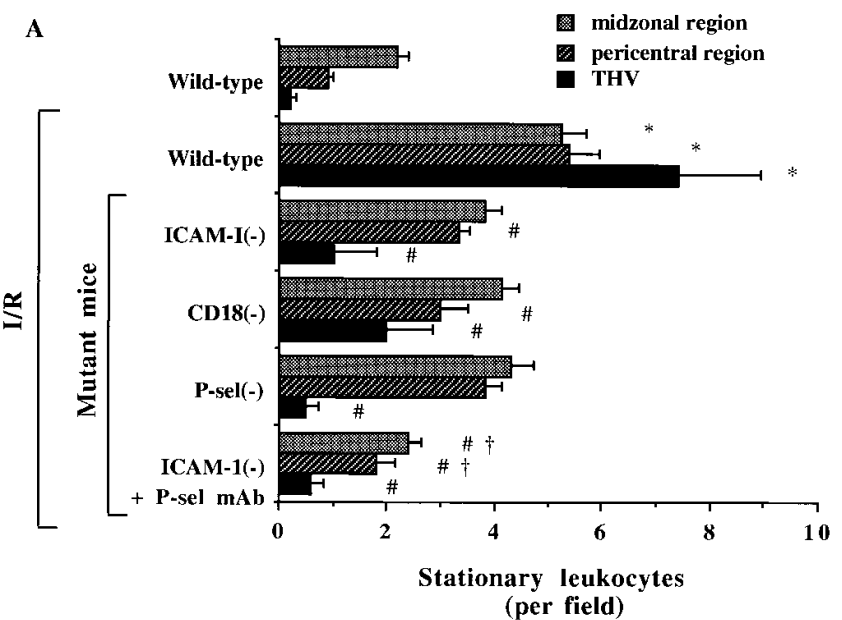

c

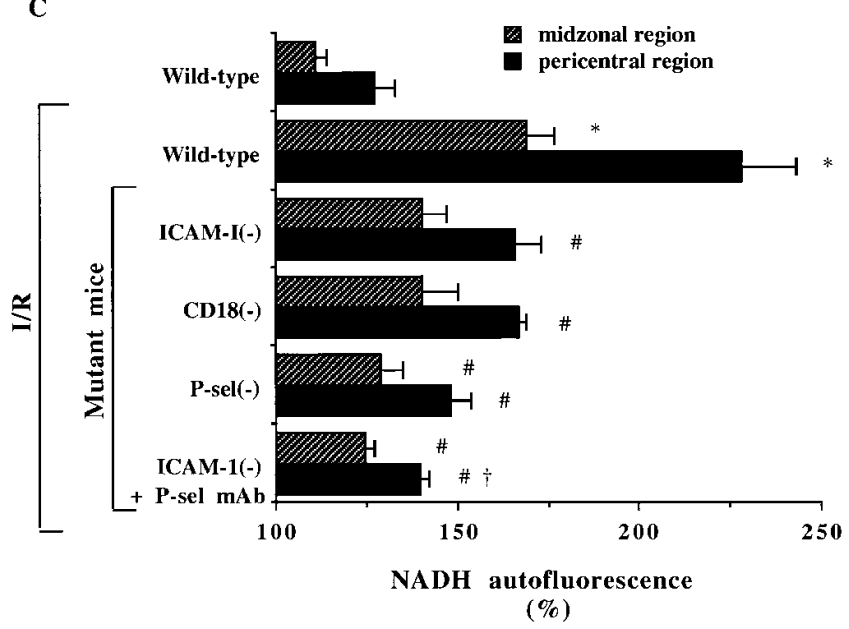

Fig. 2 summarizes the effects of gut I/R on the time course of changes in the percentage of nonperfused sinusoids in mouse liver. Even in wild-type mice not exposed to gut $\mathrm{I} / \mathrm{R}$, $<10 \%$ of sinusoids were not perfused over the 60 -min observation period. Gut I/R elicited progressive and significant increases in the number of nonperfused sinusoids, reaching a value of $33.0 \pm 2.9 \%$ at $60 \mathrm{~min}$ of reperfusion. This magnitude of the no reflow phenomenon in mouse liver is similar to that previously noted in rat liver after gut I/R (17).

Fig. 3 illustrates the changes in NADH autofluorescence observed in the midzonal and pericentral regions of liver sinusiods in control (nonischemic) and postischemic liver preparations. Under control conditions, a small increase in NADH autofluorescence was noted. However, the intensity of NADH autofluorescence was significantly increased after reperfusion, with more substantive increases noted in the pericentral region.

Fig. 4 compares the changes (at $60 \mathrm{~min}$ after reperfusion) in gut I/R-induced leukostasis (Fig. $4 A$ ), percentage of nonperfused sinusoids (Fig. $4 \mathrm{~B}$ ), and NADH autofluorescence (Fig. 4 $C$ ) in wild-type mice with those changes noted in mice that are deficient in either ICAM-1, CD18 and P-selectin, or ICAM1-deficient mice receiving an anti-P-selectin $\mathrm{mAb}$. While the magnitude of the leukocyte sequestration observed in the mid-

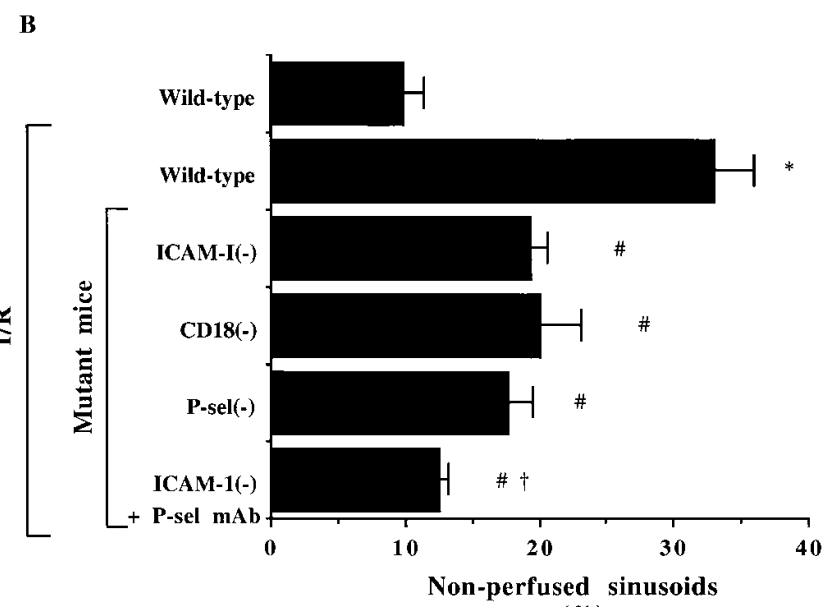

$(\%)$

Figure 4. Effects of gut ischemia/reperfusion $(I / R)$ on the number of stationary leukocytes $(A)$, percentage of nonperfused sinusoids $(B)$, and NADH autofluorescence $(C)$ in the livers of wild-type mice, mice that are genetically deficient in either ICAM-1, CD11/CD18, or $\mathrm{P}$-selectin $(P$-sel), and in ICAM-1-deficient mice receiving an anti$\mathrm{P}$-selectin monoclonal antibody. The numbers of animals in each experimental group are controls, 10; I/R, 12; each mutant mice, 6; ICAM1-deficient mice + anti-P-sel mAb, 5. ${ }^{*} P<0.05$ vs. control, ${ }^{*} P<0.05$ vs. I/R group, ${ }^{\dagger} P<0.05$ vs. ICAM-1-deficient mice.

zonal region did not differ between wild-type and all adhesion molecule-deficient mice, a significant reduction in leukocyte accumulation was noted in the pericentral region of CD11/ CD18- or ICAM-1- (but not P-selectin) deficient mice compared with wild-type controls exposed to gut I/R. The adhesion of leukocytes normally elicited by gut I/R in terminal hepatic venules of wild-type mice was signficantly blunted in THV of all the adhesion molecule-deficient mice (Fig. $4 A$ ). Similarly, the percentage of nonperfused sinusoids observed at 60 min after reperfusion in wild-type mice was lower in all of the mutant groups studied (Fig. $4 \mathrm{~B}$ ). Finally, the gut I/Rinduced elevation of NADH autofluorescence (an index of tissue hypoxia) in the pericentral region was significantly blunted in all adhesion molecule deficient mice, with some attenuation of the NADH autofluorescence response of the midzonal region noted in P-selectin knock outs. In ICAM-1-deficient mice receiving an anti-P-selectin $\mathrm{mAb}$, the reductions in gut $\mathrm{I} / \mathrm{R}-$ induced leukocyte accumulation in the midzonal and pericentral regions, percentage of nonperfused sinusoids, and elevation of NADH autofluorescence in the pericentral region were all larger than the corresponding responses noted in ICAM1-deficient mice.

Fig. 5 shows the changes in serum ALT levels (an index of hepatocellular injury) at $60 \mathrm{~min}$ after gut I/R. A significant gut 


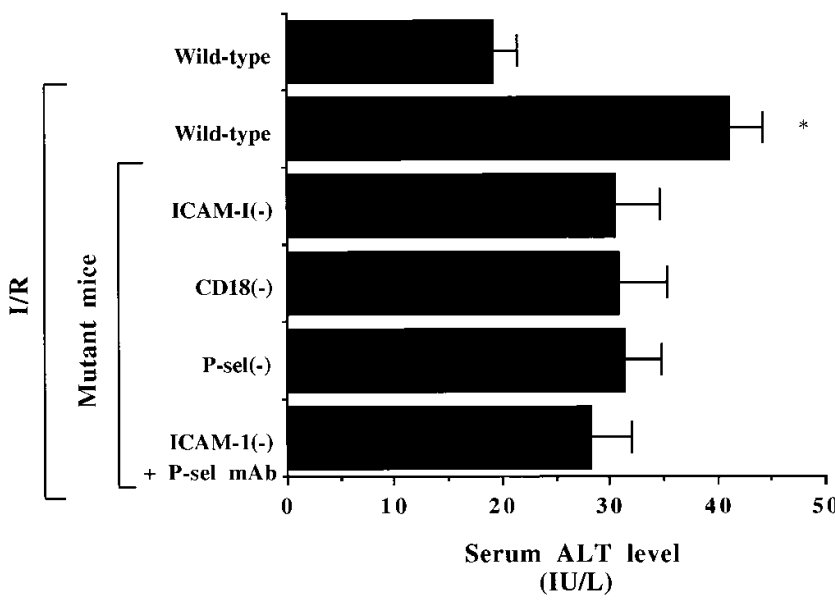

Figure 5. Serum alanine aminotransferase $(A L T)$ activity after gut $\mathrm{I} / \mathrm{R}$ in wild-type mice, mice that are genetically deficient in either ICAM-1, CD11/CD18, or P-selectin ( $P$-sel), and in ICAM-1-deficient mice receiving an anti-P-selectin monoclonal antibody. The numbers of animals in each experimental group are, controls, 10; I/R, 12; each mutant mice, 6; ICAM-1-deficient mice + anti-P-sel mAb, 5. $* P<0.05$ vs. control.

I/R-induced increase in serum ALT level was noted in wildtype mice (relative to nonischemic controls), but not in any of the mutant mice.

\section{Discussion}

There are several novel aspects of this study that extend the existing body of knowledge on the hepatic microvascular and parenchymal cell responses to gut I/R. Our study represents the first systematic evaluation of the effects of gut $I / R$ on the liver of mice, a species for which there is an ever increasing number of mutant strains (transgenics and knock outs) that should prove useful for mechanistic studies of I/R injury. Another important feature of this work is that it provides supportive evidence from adhesion molecule-deficient mice that leukocyte-endothelial cell adhesion is an important determinant of the microvascular dysfunction and tissue injury that is observed in distant organs after gut I/R. Finally, this study provides the first evidence that implicates a role for P-selectin in the hepatic leukostasis and cellular injury that is elicited by gut I/R.

Reperfusion of the ischemic intestine results in an accumulation of adherent leukocytes in THV, a reduction in the number of perfused sinusoids, increase in NADH autofluorescence (an index of tissue hypoxia), and the release of liver enzymes (ALT) into the blood stream. While these liver responses to gut I/R are qualitatively similar in the rat and mouse, some significant quantitative differences between the species do exist. For example, while it is difficult to show a significant elevation in adherent leukocytes in rat liver THV after $60 \mathrm{~min}$ of gut $\mathrm{I} / \mathrm{R}$ (11), rather profound ( $>10$-fold) increases are noted in the mouse liver over the same time frame. On the other hand, it appears that the gut $\mathrm{I} / \mathrm{R}$-induced accumulation of stationary leukocytes in the midzonal sinusoids of rat liver (11) is far more intense than that observed in mouse liver. Of interest is that the net effect of these differences between rat and mouse liver is a very similar increase in NADH autofluorescence, suggesting that the hepatocytes are exposed to a similar level of hypoxic stress after gut $\mathrm{I} / \mathrm{R}$ in both species.

There is a rapidly growing body of literature that is based on the use of genetically engineered mice to study the pathobiology of acute and chronic inflammation (13-15, 24-27). Adhesion molecule-deficient mice have been employed to assess the contribution of different adhesion glycoproteins in the recruitment of rolling and firmly adherent leukocytes in inflamed tissues such as the cremaster muscle (28). There are also a few reports that describe an improved response of ICAM-1-deficient mice (relative to wild-type mice) to different models of ischemia/reperfusion and shock. For example, it has been demonstrated in wild-type mice that 45 min of cerebral ischemia followed by $22 \mathrm{~h}$ of reperfusion is associated with an accumulation of neutrophils, an increased ICAM-1 mRNA, and tissue necrosis in the mouse brain, which are accompanied by a neurological deficit and increased mortality (29). When homozygous null ICAM-1 mice were subjected to the same $\mathrm{I} / \mathrm{R}$ protocol, the cerebral infarct volume (tissue necrosis), neurological deficit and mortality were all substantially reduced. It has also been shown that ICAM-1 knock-out mice are protected from acute renal ischemic injury as assessed by leukocyte infiltration (tissue myeloperoxidase), serum creatinine, renal histology, and animal survival (12). Finally, there is evidence in the literature that demonstrates that ICAM-1-deficient mice are resistant to the lethal effects of high doses of endotoxin, a protective response that is manifested as diminished hepatic necrosis and hemorrhage, a decrease in the systemic release of inflammatory cytokines, and improved survival (30).

Our findings in ICAM-1-deficient mice also invoke a role for this endothelial cell adhesion molecule in the pathogenesis of gut I/R-induced liver dysfunction, since the mutant mice displayed blunted inflammatory and microvascular responses as well as an attenuated hypoxic stress in the liver after gut I/R, when compared with wild-type mice. The relevance of these observations to the phenomenon of leukocyte-endothelial cell adhesion is supported by the finding that similar protection against gut I/R was noted in mice that are deficient in the leukocyte adhesion glycoprotein, CD11/CD18. This finding is consistent with the fact that $\beta_{2}$ integrins represent the major ligand for ICAM-1 on leukocytes (31) and it supports numerous published reports that invoke a critical role for CD11/ CD18-ICAM-1 interactions in the capillary plugging, leukocyte adherence in postcapillary venules, and tissue injury that is elicited in a variety of tissue by $\mathrm{I} / \mathrm{R}(32-34)$.

Another novel finding of the present study was the attenuation of gut $\mathrm{I} / \mathrm{R}$-induced liver dysfunction in P-selectin-deficient mice. P-selectin, an adhesion molecule that mediates leukocytes rolling in postcapillary venules, is produced by endothelial cells and platelets alike. In platelets, the adhesion molecule is stored in alpha granules, from which it can be mobilized to the cell surface after platelet activation to mediate platelet-leukocyte aggregation. In endothelial cells, P-selectin is stored in Weibel-Palade bodies, granules that are translocated to the cell surface in response to stimuli such as histamine, thrombin, and leukotrienes (35-37). Although there are several reports that implicate P-selectin as a mediator of leukocyte rolling in vivo, the contribution of this adhesion molecule to I/R-induced leukocyte recruitment and tissue injury remains controversial. For example, P-selectin-specific mAbs have been shown to attenuate the recruitment of neutrophils 
and reduce infarct size after $\mathrm{I} / \mathrm{R}$ in feline myocardium (38) and to reduce I/R-induced neutrophil recruitment and cellular injury in rat liver (39). However, it has also been noted that P-selectin does not affect I/R-induced leukocyte adherence and marginally reduces albumin extravasation in mesenteric venules exposed to I/R (39).

The results of this study indicate that P-selectin contributes to the liver dysfunction elicited by gut $\mathrm{I} / \mathrm{R}$ in a manner that is different from CD11/CD18 and ICAM-1. For example, leukocyte accumulation in sinusoids of midzonal and pericentral regions was reduced (relative to wild-type mice) in CD11/CD18and ICAM-1-deficient mice, but not in P-selectin-deficient mice. The lack of involvement of P-selectin in I/R-induced leukocyte adhesion in liver sinusoids may be attributed to the absence of Weibel-Palade bodies in the endothelial cells lining normal hepatic sinusoids (40). There are also immunohistochemical studies that indicate that there is no constitutive or induced expression of P-selectin in liver sinusoids (41). The fact that factor VIII-related antigen, which is stored along with P-selectin in Weibel-Palade bodies, has been localized in terminal hepatic venules is consistent with our finding that gut $\mathrm{I} / \mathrm{R}$-induced leukocyte adhesion was decreased in P-selectindeficient mice.

Although P-selectin-deficient mice did not exhibit an attenuated accumulation of leukocytes in sinusoids after gut I/R, the mutants did manifest the same reduction in the number of nonperfused sinusoids and NADH autofluorescence (hypoxic stress) as CD11/CD18- and ICAM-1-deficient mice. One possible explanation for this observation relates to the highly effective reduction in gut $\mathrm{I} / \mathrm{R}$-induced leukocyte adherence noted in the THV of P-selectin-deficient mice. Since vascular protein leakage is tightly coupled with the number of adherent and emigrated leukocytes in postcapillary venules (7), it is possible that the attenuated leukocyte adhesion in P-selectin-deficient mice also blunts the increased interstitial edema and consequent compression-induced decline in capillary blood flow (33). A second possibility is that P-selectin-directed interventions (mutants or $\mathrm{mAb}$ administration) exert their principle protective actions in the gut per se, which may then release a lower concentration of mediators that normally elicit a reduced perfusion and hypoxia in the downstream sinusoids. A final consideration is that $\mathrm{P}$-selectin contributes to the gut I/Rinduced perfusion deficit and tissue hypoxia via endotheliumindependent processes such as platelet-leukocyte aggregation $(7,42)$. This possibility is supported by our observation that the administration of a P-selectin mAb to ICAM-1-deficient mice nearly completely blocked the gut I/R-induced derecruitment of sinusoids and corresponding tissue hypoxia (with lesser responses observed in either ICAM-1- or P-selectindeficient mice). If $\mathrm{I} / \mathrm{R}$ elicits the formation of platelet-leukocyte aggregates in the gut and these aggregates are carried by the portal vein to occlude some of the arterioles that feed downstream sinusoids, then one might expect a reduced number of nonperfused sinusoids in P-selectin deficient mice compared with wild-type mice. Such a reduction in platelet-leukocyte plugging would also be expected to improve perfusion of sinusoids and reduce the hypoxic stress initiated by gut I/R. Such a mechanism may explain why P-selectin-deficient mice were the only mutants that exhibited an improved NADH autofluorescence in the midzonal region of the sinusoids, despite the absence of any attenuation of leukocyte accumulation in this segment of the sinusoid in any of the mutants studied.

\section{Acknowledgments}

This study was supported by a grant from the National Heart and Lung and Blood Institute (HL 26441).

\section{References}

1. Oliver, M.G., R.D. Specian, M.A. Perry, and D.N. Granger. 1991. Morphologic assessment of leukocyte-endothelial cell interactions in mesenteric venules subjected to ischemia and reperfusion. Inflammation. 15:331-346.

2. Lehr, H.A., A. Guhlmann, D. Nolte, D. Keppler, and K. Messmer. 1991. Leukotrienes as mediators in ischemia-reperfusion injury in a microcirculation model in the hamster. J. Clin. Invest. 87:2036-2041.

3. Engler, R.L., G.W. Schmid-Schoenbein, and R.S. Pavelec. 1983. Leukocyte capillary plugging in myocardial ischemia and reperfusion in the dog. Am. J. Pathol. 111:98-111.

4. Korthuis, R.J., M.B. Grisham, and D.N. Granger. 1988. Leukocyte depletion attenuates vascular injury in postischemic skeletal muscle. Am. J. Physiol. 254(Heart Circ. Physiol. 23):H823-H827.

5. Romson, J.L., B.G. Hook, S.L. Kunkel, G.D. Abrams, M.A. Schork, and B.R. Lucchesi. 1983. Reduction of the extent of ischemic myocardial injury by neutrophil depletion in the dog. Circulation. 67:1016-1023.

6. Simpson, P.J., R.F. Todd, J.C. Fantone, J.K. Mickelson, J.D. Griffin, and B.R. Lucchesi. 1988. Reduction of experimental canine myocardial reperfusion injury by a monoclonal antibody (anti-Mo1, anti-CD11b) that inhibits leukocyte adhesion. J. Clin. Invest. 81:624-629.

7. Kurose, I., D.C. Anderson, M. Miyasaka, T. Tamatani, J.C. Paulson, R.F Todd, J.R. Rusche, and D.N. Granger. 1994. Molecular determinants of reperfusion-induced leukocyte adhesion and vascular protein leakage. Circ. Res. 74: 336-343.

8. Poggetti, R.S., F.A. Moore, E.E. Moore, D.D. Bensard, B.O. Anderson, and A. Banerjee. 1992. Liver injury is a reversible neutrophil-mediated event following gut ischemia. Arch. Surg. 127:175-179.

9. Jaeschke, H., A. Farhood, and C.W. Smith. 1990. Neutrophils contribute to ischemia/reperfusion injury in rat liver in vivo. FASEB J. 4:3355-3359.

10. Yoshida, N., D.N. Granger, D.C. Anderson, R. Rothlein, C. Lane, and P.R. Kvietys. 1992. Anoxia/reoxygenation-induced neutrophil adherence to cultured endothelial cells. Am. J. Physiol. 262(Heart Circ. Physiol. 31):H1891H1898.

11. Horie, Y., R. Wolf, M. Miyasaka, D.C. Anderson, and D.N. Granger. 1996. Leukocyte adhesion and the hepatic microvascular responses to intestinal ischemia-reperfusion. Gastroenterology. 111:666-673.

12. Kelly, K.J., W.W. Williams, Jr., R.B. Colvin, S.M. Meehan, T.A Springer, J. Gutiérrez-Ramos, and J.V. Bonventre. 1996. Intercellular adhesion molecule-1-deficient mice are protected against ischemic renal injury. J. Clin. Invest. 97:1056-1063.

13. Sligh, J.E., Jr., C.M. Ballantyne, S.S. Rich, H.K. Hawkins, C.W. Smith, A. Bradley, and A.L. Beaudet. 1993. Inflammatory and immune responses are impaired in mice deficient in intercellular adhesion molecule 1. Proc. Natl. Acad. Sci. USA. 90:8529-8533.

14. Wilson, R.W., C.M. Ballantyne, C.W. Smith, C. Montgomery, A. Bradley, W.E. O'Brein, and A.L. Beaudet. 1993. Gene targeting yields a CD18mutant mouse for study of inframation. J. Immunol. 151:1571-1578.

15. Mayadas, T.N., R.C. Johnson, H. Rayburn, R.O. Hynes, and D.D. Wagner. 1993. Leukocyte rolling and extravasation are severely compromised in P-selectin-deficient mice. Cell. 74:541-554.

16. Lorenzl, S., U. Koedel, U. Dirnagl, G. Ruckdeschel, and H.W. Phister. 1993. Imaging of leukocyte-endothelium interaction using in vivo confocal laser scanning microscopy during the early phase of experimental pneumococcal meningitis. J. Infect. Dis. 168:927-933.

17. Villringer, A., U. Dirnagl, A. Them, L. Schürer, F. Krombach, and K.M. Einhäupl. 1991. Imaging of leukocytes within the rat brain cortex in vivo. Microvasc. Res. 42:305-315.

18. Barlow, C.H., W.R. Harden, A.H. Harken, M.B. Simson, J.C. Haselgrove, B. Chance, M. O'Connor, and G. Austin. 1979. Fluorescence mapping of mitochondrial redox changes in heart and brain. Crit. Care. Med. 7:402-406.

19. Obi-Tabot, E.T., L.M. Hanrahan, R. Cachecho, E.R. Beer, S.R. Hopkins, J.C.K. Chan, J.M. Shapiro, and W.W. LaMorte. 1993. Changes in hepatocyte NADH fluorescence during prolonged hypoxia. J. Surg. Res. 55:575-580.

20. Toth, A., M.E. Tischler, M. Pal, A. Koller, and P.C. Johnson. 1992. A multipurpose instrument for quantitative intravital microscopy. J. Appl. Physiol. 73:296-306.

21. Suzuki, H., M. Suematsu, H. Ishii, S. Kato, H. Miki, M. Mori, Y. Ishimura, T. Nishino, and M. Tsuchiya. 1994. Prostaglandin E1 abrogates early reductive stress and zone-specific paradoxical oxidative injury in hypoperfused rat liver. J. Clin. Invest. 93:155-164.

22. Suematsu, M., M. Oda, H. Suzuki, H. Kaneko, T. Furusho, S. Masushige, and M. Tsuchiya. 1993. Intravital and electron microscopic observation of Ito cells in rat hepatic microcirculation. Microvasc. Res. 46:28-42.

23. Patel, K.D., K.L. Moore, M.U. Nollert, and R.P. McEver. 1995. Neutrophils use both shared and distinct mechanisms to adhere to selectin. J. Clin. In- 
vest. 96:1887-1896

24. Bullard, D.C., L. Qin, I. Lorenzo, W.M. Quinlin, N.A. Doyle, R. Bosse, D. Vestweber, C.M. Doerschuk, and A.L. Beaudet. 1995. P-selectin/ICAM-1 double mutant mice: acute emigration of neutrophils into the peritoneum is completely absent but normal into pulmonary alveoli. J. Clin. Invest. 95:17821788 .

25. Tan, T.Q., C.W. Smith, E.P. Hawkins, E.O. Mason, Jr., and S.L. Kaplan. 1995. Hematogenous bacterial meningitis in an intercellular adhesion molecule1-deficient infant mouse model. J. Infect. Dis. 171:342-349.

26. Xu, H., J.A. Gonzalo, Y.S. Pierre, I.R. Williams, T.S. Kupper, R.S. Cotran, T.A. Springer, and J. Gutierrez-Ramos. 1994. Leukocytosis and resistance to septic shock in intercellular adhesion molecule-1-deficient mice. J. Exp. Med. 180:95-109.

27. Ley, K., D.C. Bullard, M.L. Arbonés, R. Bosse, D. Vestweber, T.F. Tedder, and A.L. Beaudet. 1995. Sequential contribution of L- and P-selectin to leukocyte rolling in vivo. J. Exp. Med. 181:669-675.

28. Kunkel, E.J., U. Jung, D.C. Bullard, K.E. Norman, B.A. Wolitzky, D. Vestweber, A.L. Beaudet, and K. Lay. 1996. Absence of trauma-induced leukocyte rolling in mice deficient in both P-selectin and intercellular adhesion molecule 1. J. Exp. Med. 183:57-65.

29. Connolly, E.S., Jr., C.J. Winfree, T.A. Springer, Y. Naka, H. Liao, S.D. Yan, D.M. Stern, R.A. Solomon, J. Gutierrez-Ramos, and D. Pinsky. 1996. Cerebral protection in homozygous null ICAM-1 mice after middle cerebral artery occlusion: role of neutrophil adhesion in the pathogenesis of stroke. J. Clin. Invest. 97:209-216.

30. Xu, H., J.A. Gonzalo, Y. St. Pierre, I.R. Williams, T.S. Kupper, R.S. Cotran, T.A. Springer, and J. Gutierrez-Ramos. 1994. Leukocyte and resistance to septic shock in intercellular adhesion molecule-1-deficient mice. 180:95-109.

31. Anderson, D.C. 1995. The role of $\beta_{2}$ integrins and intercellular adhesion molecule type-1 in inflammation. In Physiology and Pathophysiology of Leukocyte Adhesion. D.N. Granger and G.W. Schmid-Schönbein, editors. Oxford University Press, New York. 3-42.

32. Granger, D.N., I. Kurose, and P.R. Kvietys. Modulation of leukocyte adherence and emigration during ischemia and reperfusion. In Physiology and Pathophysiology of Leukocyte Adhesion. D.N. Granger and G.W. SchmidSchönbein, editors. Oxford University Press, New York. 323-338.

33. Gute, D., and R.J. Korthuis. Role of leukocyte adherence in reperfu- sion-induced microvascular dysfunction and tissue injury. In Physiology and Pathophysiology of Leukocyte Adhesion. D.N. Granger and G.W. SchmidSchönbein, editors. Oxford University Press, New York. 359-380.

34. Engler, R.L., and G.W. Schmid-Schönbein. Leukocytes in capillary networks. In Physiology and Pathophysiology of Leukocyte Adhesion. D.N. Granger and G.W. Schmid-Schönbein, editors. Oxford University Press, New York. 339-358.

35. Bonfanti, R., B.C. Furie, B. Furie, and D.D. Wagner. 1989. PADGEM (GMP140) is component of Weibel-palade bodies of human endothelial cells. Blood. 73:1109-1112.

36. Hattori, R., K.K. Hamilton, R.D. Fugate, R.P. Mc Ever, and P.J. Simps. 1989. Stimulated secretion on endothelial von Willebrand factor is accompanied by rapid redistribution to the cell serface of the intracelluar granule membrane protein GMP-140. J. Biol. Chem. 264:7768-7771.

37. Hattori, R., K.K. Hamilton, R.P. Mc Ever, and P.J. Simps. 1989. Complement protein C5b-9 induce secretion of high molecular weight multimers of von Willebrand factor and translocation of granule membrane protein GMP140 to the cell surface. J. Biol. Chem. 264:9053-9060.

38. Weyrich, A.S., X. Ma, D.J. Lefer, K.H. Albertine, and A.M. Lefer. 1993. In vivo neutralization of $\mathrm{P}$-selectin protects feline heart and endothelium in myocardial ischemia and reperfusion injury. J. Clin. Invest. 91:2620-2629.

39. Garcia-Criado, F.J., L.H. Toledo-Pereyya, F. Lopez-Neblina, M.L. Phillips, A. Paez-Rollys, and K. Misawa. 1995. Role of P-selectin in total hepatic ischemia and reperfusion. J. Am. Coll. Surg. 181:327-334.

40. Ueno, T., S. Inuzuka, T. Torimura, S. Tamaki, H. Koh, M. Kin, T. Minetoma, Y. Kimura, H. Ohira, M. Sata, H. Yoshida, and K. Tanikawa. 1993. Serum hyaluronate reflects hepatic sinusoidal capillarization. Gastroenterology. 105:475-481.

41. Steinhoff, G., M. Behrend, B. Schrader, A.M. Duijvestijn, and K. Wonigeit. 1993. Expression patterns of leukocyte adhesion ligand molecules on human liver endothelia: lack of ELAM-1 and CD62 inducibility on sinusoidal endothelia and distinct distribution of VCAM-1, ICAM-1, ICAM-2, and LFA-3. Am. J. Pathol. 142:481-488.

42. Okada, Y., B.R. Copeland, E. Mori, M.M. Tung, W.S. Thomas, and G.J. Del Zoppo. 1994. P-selectin and intercellular adhesion molecule-1 expression after focal brain ischemia and reperfusion. Stroke. 25:202-211. 